\title{
ARtigos
}

\section{Análise morfológica de remanescentes dentais de uma ossada humana encontrados em sambaqui no arquipélago de Ilhabela, litoral norte do Estado de São Paulo, Brasil}

\author{
Morphological analysis of dental remains of a human skeleton \\ found in a mountain-shell (Sambaqui) in Ilha Bela Archipelago on \\ the northern coast of São Paulo, state, Brazil
}

\author{
Marcelo Palinkas ${ }^{(1)}$, Marisa Semprini(2), Raffaela Arrabaça Francisco(3), Cíntia \\ Bendazzoli Simões ${ }^{(4)}$, Marco Aurélio Guimarães ${ }^{(5)}$, Ricardo Henrique Alves da Silva ${ }^{(6)}$
}

Palinkas M, Semprini M, Francisco RA, Simões CB, Guimarães MA, Silva RHA. Análise morfológica de remanescentes dentais de uma ossada humana encontrados em sambaqui no arquipélago de llhabela, litoral norte do Estado de São Paulo, Brasil. Saúde, Ética \& Justiça. 2010;15(2):75-9.

RESUMO: A avaliação bioantropológica em remanescentes de tecidos duros pode colaborar na identificação das características físicas dos indivíduos. Os dentes, estrutura dura que também se caracteriza por ser resistente à degradação, são importantes na identificação de corpos que passaram por grandes modificações. O objetivo deste estudo é analisar os remanescentes dentais de uma ossada humana datada de $1920 \pm 40$ anos AP localizados em sambaqui, no Arquipélago de Ilhabela - SP, Brasil, como fonte de análise anatômica para fins científicos. Os remanescentes dentais foram classificados segundo a notação dental e os autores concluíram que, mesmo com o passar do tempo, os dentes mantém características anatômicas marcantes, podendo ser de grande utilidade na identificação do indivíduo morto.

DESCRITORES: Antropologia forense; Arqueologia, Dente/anatomia \& histologia; Odontologia legal.

\footnotetext{
(1) Doutorando em Odontologia Restauradora, Faculdade de Odontologia de Ribeirão Preto - USP, Brasil.

(2) Professora Titular - Departamento de Morfologia, Estomatologia e Fisiologia, Faculdade de Odontologia de Ribeirão Preto - USP, Brasil.

(3) Mestranda, Departamento de Patologia e Medicina Legal Faculdade de Medicina de Ribeirão Preto-USP, Brasil.

(4) Doutoranda em Arqueologia, USP, Brasil.

(5) Professor Doutor - Departamento de Patologia e Medicina Legal, Faculdade de Medicina de Ribeirão Preto - USP, Brasil.

(6) Professor Doutor - Departamento de Clínica Infantil, Odontologia Preventiva e Social, Faculdade de Odontologia de Ribeirão Preto - USP, Brasil.

Endereço para correspondência: Prof. Dr. Ricardo Henrique Alves da Silva, Faculdade de Odontologia de Ribeirão Preto - USP, Avenida do Café, s/n - Bairro - Monte Alegre.- Ribeirão Preto, SP, Brasil. CEP: 14040-904. e-mail: ricardohenrique@usp.br
} 


\section{INTRODUÇÃO}

$\mathrm{O}$ exame de restos humanos em Antropologia Forense deve ser focado na identificação da vítima ${ }^{1}$, embora, em situações em que isto não é possível, permite ainda traçar seu perfil bioantropológico, incluindo gênero, idade, estatura, e ancestralidade.

A Odontologia, nesse sentido, possibilita a avaliação das características dentais, como formato e tamanho dos dentes, a análise dos desgastes ósseos e achados patológicos ou funcionais da dentição bem como o exame das variações anatômicas do indivíduo. Além disso, permite a detecção de patologias presentes, como tumores ósseos, osteoporose e osteomielite, e o relato de características individuais ${ }^{2-4}$

A identidade engloba um conjunto de caracteres que individualiza uma pessoa. Pode ser objetiva, quando permite afirmar tecnicamente que determinada pessoa é ela mesma por apresentar elementos positivos que a fazem distinta das demais, ou subjetiva, quando observa a sensação que cada indivíduo tem de sua própria pessoa, estando esta intimamente ligada à personalidade de cada um, conferindo atributos que tornam alguém igual apenas a si próprio 5 .

A interação entre a Odontologia Legal e a Arqueologia pode ajudar na identificação e caracterização morfológica do material dental de restos humanos encontrados, auxiliando na determinação do gênero, idade cronológica, hábitos culturais e alimentares e ainda na detecção de patologias orais. Quando se avaliam remanescentes dentais, torna-se importante também identificar a antiguidade do material ${ }^{6}$.

O elemento dental, mais do que o próprio osso, representa, por vezes, o único vestígio de uma espécie ou população extinta, tornando-se muito importante na identificação de corpos que passaram por grandes modificações. E a Odontologia Legal é a área da Odontologia que avalia as mudanças que ocorrem com os remanescentes dentais com o avançar dos anos e vários são os trabalhos que apresentam um caráter descritivo da morfologia dental e validam esta metodologia para o entendimento de diferentes aspectos relacionados ao modo de vida de populações humanas em tempos pretéritos.

Cameriere et al. ${ }^{7}$ relataram que o método que mostra o acúmulo de dentina secundária nos remanescentes dentais é essencial para determinar a idade da ossada humana tanto na ciência antropológica como na forense.
Oliveira et al. ${ }^{8}$ analisaram dentes extraídos de um fragmento de mandíbula humana com uma idade estimada de aproximadamente 2500 anos, proveniente de coleta assistemática no sítio arqueológico Mar Virado, Ubatuba, litoral Norte de São Paulo, e, comparando-os com dentes mais recentes, observaram que a presença de hifas de fungos na dentina distinguia os elementos de origem muito antiga.

As larguras mésio-distais dos dentes humanos podem servir para identificação do gênero da espécie e, em várias pesquisas que determinaram valores da largura dos dentes observou-se a presença de dimorfismo dental ${ }^{9-10}$.

Diferentes grupos étnicos podem ser identificados pela análise morfológica dos dentes, bem como pela avaliação de medidas antropométricas, como estatura e proporções do corpo humano, assim como pela estrutura craniofacial $^{11}$

Quando associada ao exame físico direto de uma ossada humana, a investigação dos dentes pode fornecer dados significativos para uma análise antropológica, uma vez que suas características anatômicassãoverdadeiros registrosque distinguem não só o indivíduo como populações, pela avaliação de desgastes intencionais por rituais ou utilização dos dentes como ferramentas. Outras avaliações que fornecem dados antropológicos importantes são a pesquisa de vestígios alimentares, pólen e fitólitos ${ }^{12}$

As pesquisas arqueológicas realizadas com a utilização da datação radiocarbônica para indicar idade de um dado artefato ou remanescente determinaram que a ocupação do arquipélago de Ilhabela se deu há aproximadamente dois mil anos.

O Litoral Norte do Estado de São Paulo possui sítios arqueológicos de grande relevância para o estudo das diferentes populações que ocuparam essa porção da costa brasileira. Pesquisas realizadas no âmbito do Projeto de Gestão e Diagnóstico Arqueológico do município de Ilhabela apontam que essa região abrigou inúmeros assentamentos indígenas desde a pré-história até o período colonial, a partir do qual a ocupação européia passou também a deixar marcas.

A primeira população a se estabelecer em Ilhabela, há pelo menos 2 mil anos, foi a dos construtores de sambaquis, sítios arqueológicos de cunho funerário e ritualístico formados a partir do acúmulo de conchas de moluscos em um mesmo local. Além das conchas, nesses sítios podem ser encontradas grandes quantidades de ossos de fauna marinha e terrestre, vestígios de fogueiras, 
Palinkas M, et al. Análise morfológica de remanescentes dentais de uma ossada humana.

objetos confeccionados em osso, dentes e conchas, além de artefatos feitos de pedra. Sepultamentos humanos estão presentes nos sambaquis, muitos deles adornados com colares e pingentes ${ }^{13}$.

Pouco ainda se sabe sobre dados antropológicos de pelo menos uma dezena desses sambaquis presentes no Arquipélago de Ilhabela. Torna-se premente, então, uma análise detalhada de elementos dentais achados no local, para que se possam estabelecer parâmetros científicos odontolegais, que auxiliem na compreensão do modo de vida dos indivíduos que viveram neste território em tempos pré-coloniais.

A análise de remanescentes dentais, principalmente de dentes caninos superiores e inferiores, pode permitir a identificação do gênero de uma ossada humana, mesmo que afetada pelas intempéries ambientais, baseando-se na quantidade de ácido necessária para neutralizar a dentina alcalinizada em pó, quantidade essa diferente em material de origem feminina ou masculina ${ }^{14}$.

\section{RELATO DE CASO}

Este estudo avaliou dois elementos dentários de um sambaquieiro, povo amplamente reconhecido no meio científico arqueológico e na literatura especializada como pescadores-caçadorescoletores. Em escavação de um sítio arqueológico do tipo sambaqui, foi encontrado um esqueleto humano desta população, enterrado em meio a conchas e ossos de animais dentro de um abrigo rochoso ao norte da praia de Furnas no Arquipélago de Ilhabela, Estado de São Paulo. Uma amostra do osso desse indivíduo foi enviada a um laboratório de datação radiocarbônica nos EUA e o resultado da análise revelou que este havia vivido há cerca de $1920 \pm 40$ AP (datação realizada por meio da análise de colágeno ósseo por C14), sendo este, até o momento, reconhecido como o mais antigo habitante encontrado neste arquipélago. Este foi o primeiro remanescente de sepultamento humano retirado de sítio arqueológico daquele município, e sua datação revela a ancestralidade da ocupação de Ilhabela por volta de 2 mil anos atrás.

As imagens dos remanescentes dentais foram realizadas com câmara fotográfica digital Nikkon ${ }^{\text {TM }}$ D60 de 10.2 mega pixels e lente de 18-55 $\mathrm{mm} \mathrm{Vr}$ e enviadas para análise forense.

Dentre os remanescentes dentais, foram encontrados dentes compatíveis possivelmente com molares superiores, molares inferiores e dentes anteriores superiores e inferiores com grande perda coronária.
A identificação, neste trabalho, restringiuse à análise de dois dentes molares. Observouse, nestes dentes, sua caracterização anatômica e, quando possível, a notação dental, o seu posicionamento (direito/esquerdo, superior/inferior) e as partes constituintes (presença/ausência de coroa ou raiz).

Na Figura 1, o elemento dental apresentado possui duas raízes: mesial e distal, como observado na região mediana inferior da foto, tratando-se então, de um molar inferior, do quadrante três ou quatro. A identificação quanto a possibilidade de ser um primeiro, segundo ou terceiro molar dependeria da verificação da coroa total do dente, principalmente de sua face oclusal, ausente na foto. Supõe-se, pela imagem, que seja um primeiro molar inferior direito ou esquerdo (dente 36 ou dente 46), pelo posicionamento mesial de um sulco, sendo que um primeiro molar apresenta três cúspides vestibulares, supondo que essa é a face vestibular do dente, o que o distinguiria do segundo e do terceiro molar.

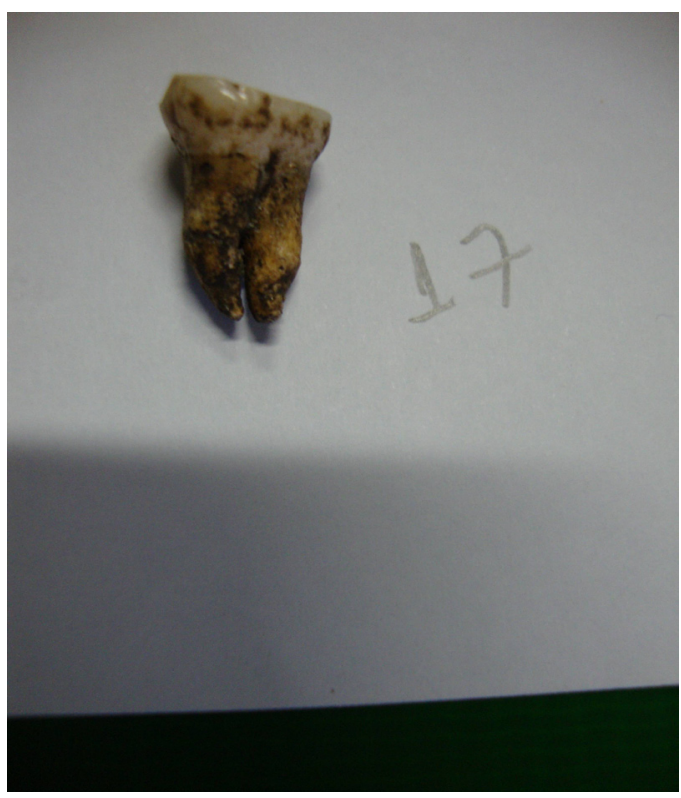

Figura 1: Visão geral de molar inferior (dente 36 ou dente 46) de um sambaquieiro

Na Figura 2, observa-se que se trata de um molar inferior do terceiro quadrante ainda fixado na mandíbula. Pela porção radicular que permite observação, a suspeita é de que seja um terceiro molar, pois as raízes parecem estar fusionadas e localizadas bem no ângulo da mandíbula.

O trígono retromolar, indica que a superfície do dente focalizada na foto seja a lingual. Supõe-se que seja um terceiro molar inferior do lado direito (dente 48). 
Palinkas M, et al. Análise morfológica de remanescentes dentais de uma ossada humana.

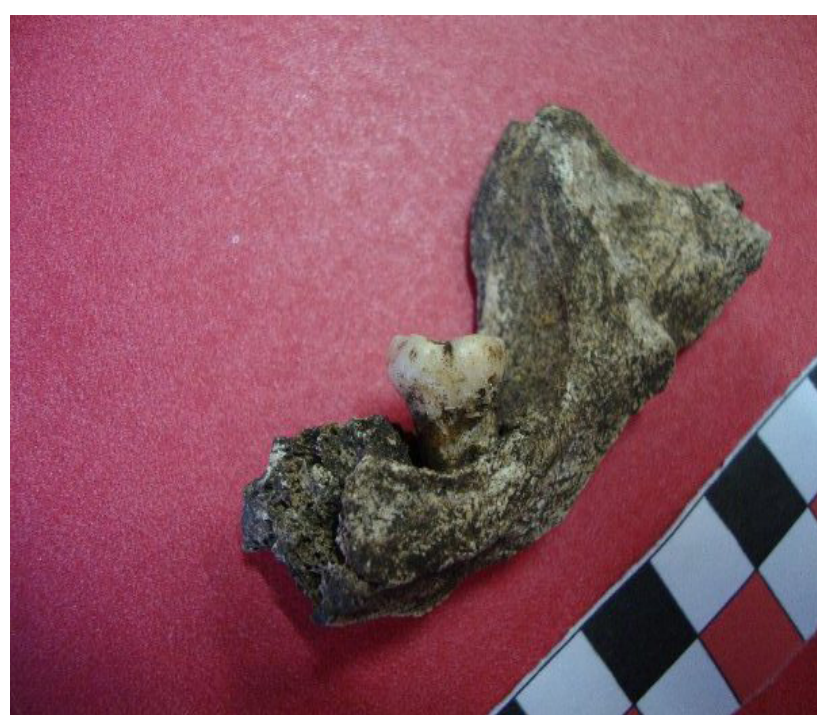

Figura 2: Elemento dental fixado em um fragmento de mandíbula

Os vestígios dentais atuam como registro das circunstâncias que afetaram as espécies durante a vida, particularmente a humana, sendo muitas vezes possível fazer a identificação do gênero da ossada e de patologias. Os remanescentes dentais avaliados neste trabalho apresentam desgastes severos resultantes, possivelmente, dos hábitos alimentares dos povos dos sambaquis.

Embora a literatura descreva variações regionais, a maioria dos sambaquieiros apresenta desgastes dentais extensos, dificultando a quantidade e a qualidade de informações que se extrai do estudo de amostras dentais e osteológicas dos mesmos. Entretanto, a análise anatômica proporciona ao pesquisador uma capacidade de apreciar e descrever os detalhes morfológicos presentes. Com isso, estudamos as estruturas do corpo de um remanescente arqueológico humano. A nomenclatura anatômica, que colabora com particularidades terminológicas das estruturas, e a Odontologia Legal, que possui técnicas apropriadas como as radiográficas, as histológicas e as antropométricas, possibilitam a identificação do ser humano.

\section{CONSIDERAÇÕES FINAIS}

O perfil anatômico dos remanescentes dentais de um indivíduo é de grande valia para a Odontologia Legal, principalmente para a identificação humana, permitindo que estudos bioantropológicos sejam realizados. No caso em questão, foi possível supor quais eram os elementos dentais analisados apesar das condições de acentuado desgaste dos dentes em relação às amostras rotineiramente analisadas na prática da odontologia forense. Novas análises arqueológicas de outros remanescentes ósseos humanos serão necessárias para a compreensão de aspectos morfológicos dentais em esqueletos encontrados em escavações de sepultamentos em sambaquis.

Palinkas M, Semprini M, Francisco RA, Simões CB, Guimarães MA, Silva RHA. Morphological analysis of dental remains of a human skeleton found in a mountain-shell (Sambaqui) in Achipelago llhabela, northern coast of São Paulo, Brazil. Saúde, Ética \& Justiça. 2010;15(2):75-9.

ABSTRACT: The bioanthropological evaluation on remains of hard tissues can collaborate in identifying physical characteristics of individuals. The teeth are important in the identification of human bodies that have undergone major changes particularly due to its resistance to degradation. The aim of this study is analyzing the dental remains of a human skeleton - dated of $1920 \pm 40$ years BP and located in a shell mound at the llhabela Archipelago, São Paulo State, Brazil - as a source of anatomical analysis for scientific purposes. The remaining teeth were classified according to dental notation and the authors concluded that even in a long time, teeth keep maintain anatomical features which may be helpful in identifying the deceased individual.

KEYWORDS: Forensic anthropology; Archaeology; Tooth/anatomy \& histology; Forensic dentistry.

\section{REFERÊNCIAS}

1. Komar DA, Buikstra JE. Forensic anthropology: contemporary theory and practice. New York: Oxford University Press; 2008.

2. White TD, Folkens $P$ A. the human bone manual.
New York: Academic Press; 2004.

3. Mann RW, Hunt DR. Photographic regional atlas of bone disease. 2rd ed. Springfield, III.: Charles C. Thomas; 2005. 
Palinkas M, et al. Análise morfológica de remanescentes dentais de uma ossada humana.

4. Byers SN. Forensic anthropology laboratory manual. 2rd ed. Valencia: University of New Mexico; 2007.

5. França GV. Medicina legal. 7a ed. Rio de Janeiro: Guanabara Koogan; 2004.

6. Oliveira RN, Melani RFH, Antunes JLF, Freitas ER, Galvão LCC. Postmortem tooth loss in human identification process. J Forensic Odontostomatol. 2000;18:32-6.

7. Cameriere R, Ferrante L, Cingolani M. Variations in pulp/tooth area ratio as an indicator of age: a preliminary study. J Forensic Sci. 2004;49:317-9.

8. Oliveira RN, Silva SFS, Uchôa DP, Mesquita RA, Nunes FD. Fungal infiltration in the human dentine: archaeology and forensic implications. Cienc Odontol Bras. 2004;7(3):87-90.

9. Yamaguto OT, Vasconcelos MHF. Determination of mesiodistal dental measures in White Brazilian individuals with normal occlusion. Rev Dent Ortodon Ortop Facial. 2005;10(5).

10. Cavalcanti AL, Porto DE, Maia AMA, Melo TRNB. Estimativa da estatura utilizando a análise dentária: estudo comparativo entre o método de Carrea e o método modificado. Rev Odontol UNESP. 2007;36(4):335-9.

11. Sampaio CMA. Avaliação do índice de Carrea comparado ao índice cefalométrico de Retzius e índice facial [Dissertação]. Piracicaba: Faculdade de Odontologia de Piracicaba, Universidade de Campinas; 1995.

12. Oliveira RN, Silva SFS, Uchôa DP, Mesquita RA, Nunes FD. Fungal infiltration in the human dentine: archaeology and forensic implications. Cienc Odontol Bras. 2004;7(3):87-90.

13. Bendazzoli, C, Francisco R, Guimarães MA. Arqueologia de um sambaqui em abrigo, Ilhabela - SP. Rev Museu Arqueol Etnol, São Paulo. 2009;19:381-91.

14. Galvão LCC, Júnior JAR, Cunha JOA. Odontologia legal: aspectos históricos. 2007. Disponível em: http://www.portaleducacao.com.br/odontologia/ artigos/2544/odontologia-legal-aspectos-historicos.

15. Simões CB. O processo de formação dos Sambaquis: uma leitura estratigráfica do Sitio Jabuticabeira II, SC [dissertação]. São Paulo: Universidade de São Paulo; 2007.

Recebido em: 12/05/2010

Aprovado em: 30/10/2010 